\title{
Low Emission Steelmaking
}

\author{
Sharif Jahanshahi $^{1,2} \cdot$ John G. Mathieson ${ }^{3} \cdot$ Henk Reimink $^{4}$
}

Published online: 14 June 2016

(C) The Minerals, Metals \& Materials Society (TMS) 2016

\section{Preface}

Steel is one of the most important structural materials in the world. It is used in virtually all industry sectors and, after cement, is the leading manmade material produced, with the annual production rate reaching 1660 million tonnes in 2014 [1].

Through continuous development and implementation of incremental technologies, the steel industry has improved its energy efficiency and reduced its specific energy consumption by about $60 \%$ over the past 50-60 years. The close linkage between energy consumption and $\mathrm{CO}_{2}$ emission has resulted in a similar reduction in specific $\mathrm{CO}_{2}$ emission, where currently about $2.2 t \mathrm{CO}_{2}$ is produced per tonne of crude steel manufactured through efficient integrated blast furnace and BOF plants [2].

Climate Change was understood fairly early in Europe not only as a challenge for society, but also as an opportunity for the carbon-intensive steel sector to explore radically new steel production technologies, even before the Kyoto protocol was signed [3]. Many wide-ranging studies were conducted to identify solution paths at a company level and in an international context [4-6]. The work carried out then showed that to reduce the specific emissions

The contributing editor for this article was S. Kitamura.

Sharif Jahanshahi

sharif@unsw.edu.au

CSIRO, Melbourne, Australia

2 Present Address: Metal-Logical Solutions, Melbourne, Australia and UNSW, Sydney, Australia

3 BlueScope Steel Research, Port Kembla, NSW, Australia

4 World Steel Association, Evere, Belgium of the steel sector to the level of climate change expectation, i.e., $50 \%$ or preferably more, it was necessary to introduce deep paradigm changes in the way steel is made, as the existing production routes had only a small leeway for improvement, $15 \%$ or less for the world class steel mills.

Similarly, in Japan work commenced in 1999 on a fiveyear feasibility study on "Innovative Ironmaking Reactions in New BF to Aim at Halving Energy Needs and Minimising Environmental Load." This project involved the four major steelmakers and 12 universities and other institutions. It was coordinated by Professor Kuniyoshi Ishii for the ISIJ and has often been termed the "Ishii Project" [7].

In the early 2000s, conditions seemed prospective in Europe in terms of a favorable political context to move from paper studies to the experimental exploration of solutions. Indeed, the EU had started taking the lead in announcing the type of low-carbon economy that would be necessary. A large consortium of 40 partners was brought together, comprising most of the steel sector in the EU and many Universities and Research Centres from 11 countries. A research proposal, answering a coordinated European Research call from the United Nations' 6th Framework Program on climate change and the Research Fund for Coal and Steel (RFCS), was presented and won the competition in 2004. Thus, the 5-year Ultra Low $\underline{\mathrm{CO}}_{2} \underline{\text { Steel (ULCOS) }}$ production program was born, coordinated by Dr. JeanPierre Birat of ArcelorMittal.

At that time, Dr. Birat was also active at the International Iron and Steel Institute renamed in 2008 to the World Steel Association (worldsteel) and initiated its $\mathrm{CO}_{2}$ Breakthrough Coordination Program, which allowed contributions from all regions/countries to the development of technologies that could result in at least $50 \%$ reduction in 
the $\mathrm{CO}_{2}$ emission. This international program covered the European ULCOS, Japanese COURSE50, North American AISI and Australian $\mathrm{CO}_{2}$ Breakthrough programs as well as the developments by China, South Korea and Taiwan. A summary of these programs is provided below, followed by a number of invited review or research articles in this thematic section of Journal of Sustainable Metallurgy.

\section{Ultra Low Carbon Dioxide Steelmaking (ULCOS)}

The objective of ULCOS was to come up with steel making technologies that would cut GHG emissions by at least $50 \%$. No single solution was assumed at the onset of the work, and the likely time scale needed for moving the various low- $\mathrm{CO}_{2}$ technologies up to a technology readiness level (TRL) ${ }^{1}$ of 8 or 9 would extend to 20 years or more. Furthermore, to ensure robustness over this long period several options had to be kept open. The focus was on the production of steel from iron ore and coke as it was acknowledged that steel recycling using the electric arc furnace (EAF) had already reached a very high level (about $90 \%$ ) and with $100 \%$ scarp $0.5 t \mathrm{CO}_{2} / t$ crude steel. This had already helped the steelmaking sector decrease its emissions in the twentieth century. Given the on-going lack of scrap availability, then further progress could only be made through steel production from primary raw materials.

A first step in the program carried out a complete review of the various options open for drastically cutting $\mathrm{CO}_{2}$ emissions and about 80 of them were identified. In terms of process families, this included the following:

- Smelting-reduction based on coal/coke, i.e., from the Blast Furnace to new processes like HIsmelt and more;

- Direct reduction based on natural gas and hydrogen;

- Electrolysis of iron ore based on various concepts; and

- Bio-carbon based steelmaking, again using a number of reactors.

It was realized during the early stages that apart from biomass-based technologies, none of the proposed new technologies would achieve the target of $50 \%$ plus reduction without being complemented by carbon capture, reuse or storage (CCUS, CCS). Thus, CCS was applied to most processes, even to the bio-carbon-based ones that would therefore act as a pump of $\mathrm{CO}_{2}$ from the atmosphere.

Where needed, laboratory work was carried out to provide the modelers with experimental data. Modeling of energy consumption and emissions was carried out using a steel plant simulator within clearly specified boundaries

\footnotetext{
1 TLS or technology readiness levels are a method of estimating technology maturity and are based on a scale of 1-9, with TLS 9 being most mature technology i.e., system fully tested, demonstrated and into operation. See "Technology Readiness Assessment (TRA) Guidance”, United States Department of Defence. April 2011.
}

that were complete and consistent for the whole range of solutions considered, thus including direct (steel mill) and indirect (energy-generation) emissions and incorporating cokemaking, pelletizing or sintering, production of lime and oxygen, power and steam plants, etc. in the boundary of a steel mill that delivered hot rolled products. When hydrogen was used, its generation plant was included within the boundary of the mill and the same was true of bio-carbon, thus incorporating for example a eucalyptus plantation and pyrolysis plant within in the boundaries.

The various routes were also compared in terms of operating and investment costs in a green field context and a full LCA study was added. A sophisticated foresight study was carried out to project all of the above from the present to 2050, using a scenario method, with the corresponding modeling developed for the study. The results of the simulations carried out were published in 12 papers in two special issues of Revue de Métallurgie [8, 9].

In order to move beyond the simulation and laboratory studies of the initial phase of ULCOS, a process was set up to select the solutions that met the program criteria. The outcome was a series of ULCOS solutions that were considered to be the most prospective candidates to move up the TRL scale. The selection was harsh and left behind a number of potential solutions, which were considered as high risk in the program, for funding and time scale, like hydrogen reduction or charcoal-based smelting reduction, for example.

The so-called "ULCOS solutions" are shown in Fig. 1. Three of them are variants of existing fossil reducing agent-based processes-coal or natural gas, in which most of the reduction in $\mathrm{CO}_{2}$ emissions is accomplished by CCS; however, all three are designed to reduce emission, at the level of 20-25\%, due to the features added with respect to the conventional processes. The ULCOS-BF blast furnace, for example, reinjects the top gas at the tuyeres after $\mathrm{CO}_{2}$ has been separated and sent to storage-pure oxygen is injected at the tuyeres, thus removing nitrogen from the system and avoiding its accumulation in the recirculating loop.

The fourth solution is based on electrolysis, either operated on an aqueous solution of powdered ore at about $100{ }^{\circ} \mathrm{C}$ or on a liquid bath of iron and slag reducing hematite in a conducting slag.

All these processes have been developed in the continuation of the project and in further studies, mainly by RFCS [10-12].

The ULCOS-BF was tested at the level of a $1.5 \mathrm{t} / \mathrm{h}$ in the experimental blast furnace in Luleå, Sweden, in a series of campaigns where the detailed conditions of recycling and injection were chosen and optimized. It was then decided to scale the process up to TRL7, by installing the technology on a production $\mathrm{BF}\left(1.7 \mathrm{M} t_{\mathrm{HM}} /\right.$ 


\begin{tabular}{|c|c|c|c|}
\hline \multicolumn{2}{|c|}{ Coal \& Sustainable biomass } & Natural gas & Electricity \\
\hline Revamped BF & Greenfield & Revamped DR & Greenfield \\
\hline ULCOS-BF & Hlsarna & ULCORED & ULCOWIN \\
\hline
\end{tabular}

Fig. 1 The four ULCOS solutions selected for the continuation of the ULCOS program, according to Birat et al. [10]

year, hearth diameter of $9.4 \mathrm{~m}$, inner volume of $1532 \mathrm{~m}^{3}$ ) in Florange, France. A geological storage system was studied and a suitable location in a water aquifer was selected. However, the economic crisis of 2008 forced ArcelorMittal, the Blast Furnace operator, to close down the facility, and the French government removed the project from the list of candidates for NER300 funding at the end of 2012. Since then, the project has been put on hold while continuing research on some technological themes and waiting for a better business model to finance its cost.

The HIsarna process was scaled up to an $8 \mathrm{t} / \mathrm{h}, 4 \mathrm{~m}$ diameter bath smelter, with a cyclone at the top where iron is injected and melted before feeding the reactor sitting underneath, as a liquid phase. Several campaigns were conducted in the Tata Steel Ijmuiden steel mill since the start-up of the pilot in 2010 and they are continuing with success. An extensive trial is being scheduled to start in late 2016 and running into 2017 [13].

The ULCORED concept has been developed mainly at the simulation level. Pilot tests are awaiting the construction of a suitable plant, delayed by the economic crisis.

Work on electrolysis has continued through several further projects. ULCORED can now routinely produce $4 \mathrm{~kg}$ samples of iron at ArcelorMittal research laboratories in Maizières, France.

ULCOLYSIS has by now produced a few grams of product.

The ULCOS program is continuing at a reduced pace in the wake of the 2008 financial crisis, which has not relented yet in the steel sector in Europe. The HIsarna project is the one effectively proceeding.

\section{COURSE 50}

Over the past decades, the Japanese steel industry has achieved the world's best level of energy efficiency through continuing effort in development and implementation of energy efficient and hence $\mathrm{CO}_{2}$ reduction technologies. Further reduction in $\mathrm{CO}_{2}$ emission requires development of innovative technologies with potential for step-change cuts in energy and $\mathrm{CO}_{2}$ emission.

The "Cool Earth 50" initiative, announced by Japanese Prime Minister Shinzo Abe in May 2007, proposed to achieve environmental protection and economic growth through the utilization of innovative energy saving technologies. The steel industry of Japan responded to this with an initiative "COURSE 50" or " $\mathrm{CO}_{2}$ Ultimate Reduction in Steelmaking Process by Innovative Technology for Cool Earth 50" and this was established and positioned as one of the "Innovative Technology Developments."

COURSE 50 aims at developing technologies to reduce $\mathrm{CO}_{2}$ emissions by about $30 \%$ through $\mathrm{CO}_{2}$ capture and removal from blast furnace gas as well as greater use of hydrogen and reformed coke oven gas in the blast furnace. COURSE 50 also aims to capture and utilize unused waste heat from steel plants for the proposed $\mathrm{CO}_{2}$ capture and separation processes. The progress made so far in COURSE 50 has passed successful large-scale piloting and is outlined in the series of articles in this thematic section of Journal of Sustainable Metallurgy. 
Table 1 Applications of biomass-derived chars in ironmaking and steelmaking

\begin{tabular}{ll}
\hline Integrated BF-BOF route & EAF scrap-melting route \\
\hline Sintering solid fuel & Charge carbon \\
Cokemaking blend component & Slag foaming agent \\
BF lump charcoal top charge ${ }^{\mathrm{a}}$ & Electrodes \\
BF nut coke replacement & Liquid steel ladle-recarburiser \\
BF carbon/ore composites (unreduced) & \\
BF pre-reduced feed & \\
BF tuyere fuel injectant & \\
BOF pre-reduced feed (scrap substitute) & \\
BOF fuel (scrap melting) & \\
Liquid steel ladle-recarburiser &
\end{tabular}

${ }^{a}$ Charcoal has insufficient load-bearing strength for the main coke charge to medium and large blast furnaces; however, a small proportion of smaller charcoal may have advantages. Charcoal is routinely the total top charge for mini-BFs, e.g., Brazilian practice
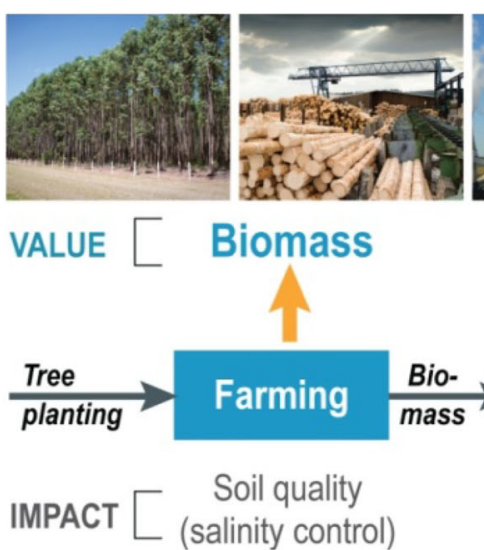
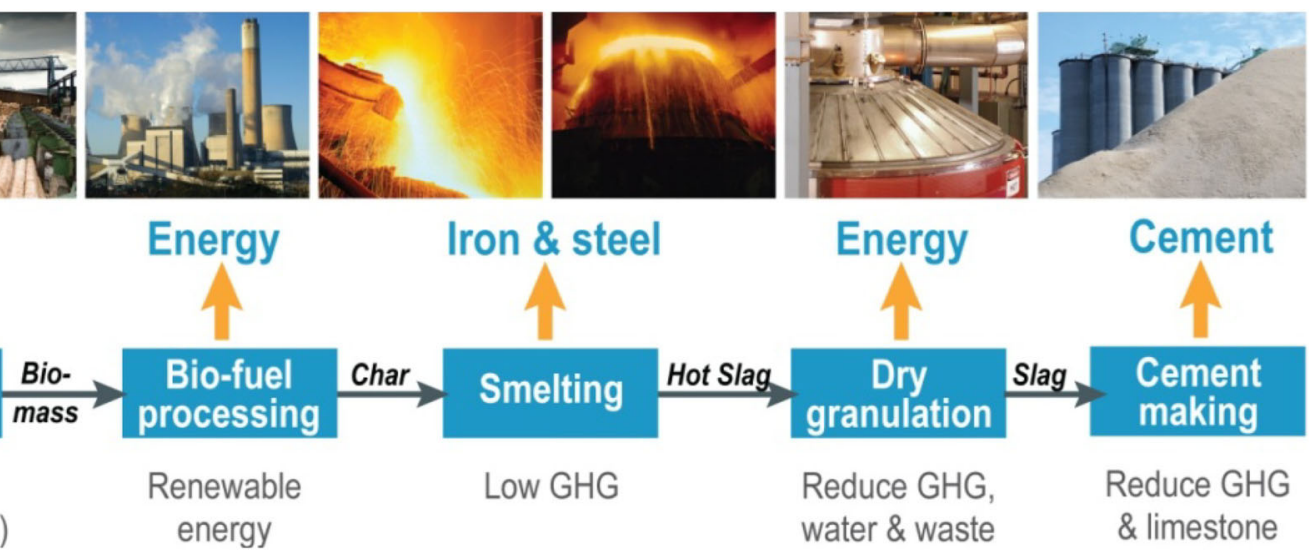
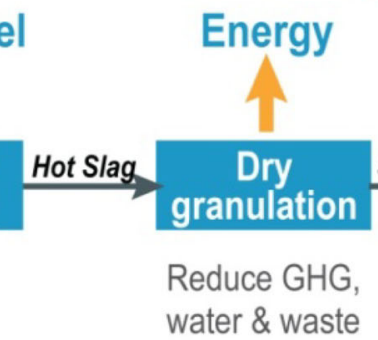

Cement

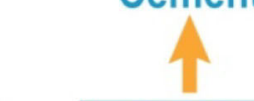

Slag Cement making

Reduce GHG \& limestone

Fig. 2 The conceptual flowsheet across the value chain for the low-emission integrated steelmaking process (ISP) [15]

It is worth noting that other substantial initiatives have taken place in Japan as extensions of "Ishii Project". These have been reviewed by Takeda et al. [14].

\section{Australian CO2BTP and ISP}

The Australian $\mathrm{CO}_{2}$ Breakthrough Program (CO2BTP) was launched in late 2006 as the nation's contribution to WSA's similarly named initiative. Funding was by the two steel companies, BlueScope and Arrium, and the Australian government via the national research organization CSIRO. The program concluded in 2015 and was also named the low-emission integrated steelmaking process (ISP) in the final years. Two main areas have been explored:

(1) The use of purpose-designed biomass-derived chars as substitutes for coal and coke. Such products have near net-zero $\mathrm{CO}_{2}$ emissions if produced from sustainably managed plantations.

(2) The granulation of molten slag without the need for water quenching, termed dry slag granulation (DSG).

Table 1 shows the 13 applications identified for biomass-derived chars (charcoals) in both the integrated BF$\mathrm{BOF}$ and EAF steelmaking routes. Key properties of the optimized char types have been provided by Jahanshahi et al. [15] and Mathieson et al. [16].

The potential for $\mathrm{CO}_{2}$ emission reduction has been estimated to be between 0.7 and $1.4 t-\mathrm{CO}_{2} / t$ crude steel for the BF-BOF route, and between 0.04 and $0.06 t-\mathrm{CO}_{2} / \mathrm{t}$ crude steel for the EAF route, making this approach the most effective means for reducing net $\mathrm{CO}_{2}$ emissions in the steel industry, especially in the short and medium terms. An added advantage is that current iron and steelmaking process equipment will require little or no change. 
Not only did the biomass project study the individual applications shown in Table 1 up to industrial scale in some cases, but it also covered biomass supply [17], life-cycleassessment $[2,16]$, and the development of a novel highproduction, high-yield, autogenous pyrolysis process [15, 18].

The DSG project identified the spinning-disc approach as having the greatest potential to disperse and solidify molten slags into a granulated product suitable for incorporation into ordinary portland cement (OPC). Initial emphasis was on the elimination of problems that had plagued previous attempts, e.g., the formation of slag-wool, and to build-in effective heat recovery by using a compact design that allowed the temperature of the cooling air to rise above $500{ }^{\circ} \mathrm{C}$. Very strong progress has been achieved and the process has been demonstrated at the $1 \mathrm{t} / \mathrm{h}$ scale $[15,19]$.

The overall concept of the low-emission integrated steelmaking process is illustrated in Fig. 2. As well as providing steel products with low greenhouse gas (GHG) emissions, it has advantages in soil management, renewable energy and provides low-GHG cement-based building products.

\section{American Iron and Steel Institute (AISI)}

The North American steel industry has demonstrated that GHG emissions are best addressed through increased research and development and the deployment of innovative technologies. Due to the close relationship between energy use and GHG emissions, the North American steel industry has achieved a $32 \%$ reduction in energy intensity and a $37 \%$ reduction in greenhouse gas intensity since 1990 .

However, the industry recognizes that in order to make major reductions in future energy/ $\mathrm{CO}_{2}$, new methods of making steel will require completely fresh and innovative thinking. The North American steel industry has been actively investing in research and development into new transformational processes for making steel that will dramatically reduce or eliminate $\mathrm{CO}_{2}$ emissions. This $\mathrm{R} \& \mathrm{D}$ is called the AISI $\mathrm{CO}_{2}$ Breakthrough Program.

The current long-term program consists of two projects $[20,21]$. The first with Massachusetts Institute of Technology is to produce iron by molten oxide electrolysis. The second project focuses on suspension reductive smelting of iron ore using hydrogen as fuel and reductant. This "Hydrogen Flash Smelting" R\&D is being conducted at the University of Utah, where coke is replaced with hydrogen, natural gas or a combination. Both projects represent significant steps towards carbon-free ironmaking, since both will have near-zero $\mathrm{CO}_{2}$ emissions if successful, providing that the electricity or hydrogen used comes from carbonfree sources.

In the near term, the AISI program has been developing the Paired Straight Hearth Furnace, which is a high- productivity, low-energy ironmaking unit that can process steel plant wastes, as well as virgin iron materials. This project has been carried out at the McMaster University and uses coal instead of coke. This type of furnace should be available for commercial demonstration in $<5$ years and will potentially achieve a significant reduction in energy use compared to current technologies. Also under consideration in the AISI $\mathrm{CO}_{2}$ breakthrough program, are $\mathrm{CO}_{2}$ sequestration projects.

\section{Other International Programs}

The POSCO (South Korea) program aims to find new solutions for $\mathrm{CO}_{2}$ emission reduction in the steel industry, and climate change adaptation using steelmaking byproducts [22]. The program consists of six projects:

1. Pre-reduction of, and heat recovery from hot sinter;

2. $\mathrm{CO}_{2}$ absorption using ammonia solution;

3. Bio-slag utilization for the restoration of marine environments;

4. Hydrogen production using COG and wastes;

5. Iron ore reduction using hydrogen-enriched syngas; and

6. Carbon-lean version of the FINEX process.

The China Steel Corporation (Taiwan) program has been focused on carbon capture and storage, where both amine- and ammonia-based solvents have been assessed through laboratory and pilot scale tests [23]. Future work includes optimization of $\mathrm{CO}_{2}$ capture technology using ammonia-based solvent and examining alternative storage technologies.

Bao Steel (Mainland China) started its reduced-carbon production program [24] in late 2013 with a focus on energy conservation and use of waste heat from slag. A solar panel development program was started and has been developed to use the large areas of the steelmaking sites rooves to capture energy and use this for non-critical plant operation.

Also the Lanzatech system [25] of making ethanol from the BOF gas ( $\mathrm{CO}$ content is the source) has been expanded from a laboratory plant to a commercial plant.

In this issue of JSM, we present three papers on the COURSE 50 initiative as well as two other invited papers on hydrogen flash/suspension smelting of iron ore and high-temperature properties of iron ore-charcoal briquettes.

\section{References}

1. Statistics Archive, WordSteel Association. http://www.world steel.org/statistics/statistics-archive.html. Accessed 23 May 2016 
2. Norgate TE, Haque N, Somerville M, Jahanshahi S (2012) Biomass as a source of renewable carbon for iron and steelmaking. ISIJ Int 52:1472-1481

3. Birat J-P, Antoine M, Dubs A, Gaye H, de Lassat Y, Nicolle R, Roth J-L (1993) Vers une sidérurgie sans carbone? Rev Métall 90:411-421

4. Birat JP, Vizioz JP, Jeanneau M, Schneider M, de Lassat Y (1999) $\mathrm{CO}_{2}$ emissions of the steel industry's available responses to the greenhouse effect. Rev Métall CIT 96(10)

5. Birat J-P, Cairns CJ, Choi J-O, Den Hartog H, Kohl B, Nishino M, Peace J, Reitzhuber F, Schafer RA, Sharma R, Schmidt G, Smith B, Werner C, Wibberley L, Iguchi S, Butterworth P, Kawai Y, Price E (2000) Review of energy developments and options to reduce $\mathrm{CO}_{2}$ emissions. Committee on Technology, IISI

6. Birat JP (2001) Greenhouse Gas Emissions of the Steel Industry-Avenues open for a Responsible and Sustainable Management of Emissions, in Greenhouse Gases in the Metallurgical Industries: Policies, Abatement and Treatment, editor C.A. Pickles, COM 2001, August 2001, Toronto, MetSoc, 89-101

7. Ishii K (2004) Preface to the special issue on innovative ironmaking reactions in new BF to aim at halving energy needs and minimizing environmental load. ISIJ Int 44(12):1969

8. 4th ULCOS SEMINAR (Part 1) (2009) Rev Met Paris 106(9)

9. 4th ULCOS SEMINAR (Part 2) (2009) Rev Met Paris 106(10)

10. Birat J-P, Borlée J, Lavelaine H, Sert D, Négro P, Meijer K, Stel JVD, Sikstrom P (2012) ULCOS program: an update in 2012, 4th international conference on process development in iron and steelmaking, Luleå, Sweden, 10-13 June 2012

11. Birat J-P (2009) Addressing the climate change challenge: the ULCOS breakthrough program, Tokyo, ISIJ 157th meeting, 30 March 2009, CAMP-ISIJ, 01/03/2009

12. Birat J-P, Borlée J, Korthas B, van der Stel J, Meijer K, Günther C, Halin M, Bürgler T, Lavelaine H, Treadgold C (2008) ULCOS program: a progress report in the Spring of 2008, SCANMET III, 3rd international conference on process development in iron and steelmaking, 8-11 June 2008, Luleå, Sweden

13. Meijer K, Treadgold C, Zeilstra C, Keilman G, Teerhuis C, Ouwehand M, van Boggelen J, Borlée J, Wagner D, Grisvard C, Feilmayr C, Thaler C, Lövgren J, Sikström P, Doppler K-G, Günther C, Feiterna A, Skorianz M, Taszner Z, Hirsch A, Sgura A, Schott R, Höcker Y, Goedert P (2015) HIsarna experimental campaigns B and C (HISARNA B and C), Final report, EUR $27515 \mathrm{EN}$.
14. Takeda K, Anyashiki T, Sato T, Oyama N, Watakabe S, Sato Michitaka (2011) Recent developments and mid- and long-term $\mathrm{CO}_{2}$ mitigation projects in ironmaking. Steel Res Int 82:512-520

15. Jahanshahi S, Mathieson JG, Somerville MA, Haque N, Norgate TE, Deev A, Pan Y, Xie D, Ridgeway P, Zulli P (2015) Development of low-emission integrated steelmaking process. J Sustain Metall 1:94-114. doi:10.1007/s40831-015-0008-6

16. Mathieson JG, Somerville MA, Deev A, Jahanshahi S (2015) Utilization of biomass as an alternative fuel in ironmaking. In: $\mathrm{Lu}$ L (ed) Iron ore mineralogy, processing and environmental sustainability. Metals and surface engineering, Woodhead Publishing, Sawston, p 581-614

17. Haque N, Somerville MA, Jahanshahi S, Mathieson JG, Ridgeway P (2008) Survey of sustainable biomass for the iron and steel industry. In: Bioenergy Australia 2008 Conference-Sustainable Bioenergy Opportunities for Australia, 8-10 December 2008, Melbourne

18. Deev A, Donnelly J, Jahanshahi S, Mathieson JG (2015) Autogenous pyrolysis process for efficient production of renewable carbon for the steel industry. In: International conference on proceedings of METEC and 2nd European Steel technology and application days (ESTAD 2015), Dusseldorf, Germany, 15-19 June 2015

19. Jahanshahi S, Xie D (2012) Current status and future direction of CSIRO's dry slag granulation process with waste heat recovery. In: 5th International Congress on the Science and Technology of Steelmaking 2012 (ICS 2012); 1-3 October 2012; Dresden, Germany. ICS 2012 Organisers; 2012

20. $\mathrm{CO}_{2}$ Breakthrough Factsheets, Steelworks, the online resource for steel, AISI. http://www.steel.org/making-steel/technology/pub lications/co2-breakthrough-factsheets.aspx. Accessed 23 May 2016

21. Containers, Steelworks, the online resource for steel. http://www. steel.org/sustainability/energy-reduction/co2-breakthrough-program.aspx. Accessed 23 May 2016

22. POSCO. https://www.posco.co.kr/homepage/docs/eng3/html/sus tain/environ/environment_04.jsp. Accessed 23 May 2016

23. China Steel website, http://www.csc.com.tw/csc_e/hr/green4. htm. Accessed on 23 May 2016.

24. Environment Management, BaoSteel. http://www.baosteel.com/ group_en/contents/2929/40180.html. Accessed 23 May 2016

25. Technical Overview, LanzaTech. http://www.lanzatech.com/ innovation/technical-overview/. Accessed 23 May 2016 